\title{
Patterns of longitudinal and tangential maturation stresses in Eucalyptus nitens plantation trees
}

\author{
Bruno Clair • Jérôme Alteyrac • Arthur Gronvold • \\ Jaime Espejo $\cdot$ Bernard Chanson • Tancrède Alméras
}

Received: 25 February 2013 / Accepted: 18 July 2013 /Published online: 19 September 2013

(C) The Author(s) 2013. This article is published with open access at Springerlink.com

\begin{abstract}
- Context Tree orientation is controlled by asymmetric mechanical stresses set during wood maturation. The magnitude of maturation stress differs between longitudinal and tangential directions, and between normal and tension woods.

- Aims We aimed at evaluating patterns of maturation stress on eucalypt plantation trees and their relation with growth, with a focus on tangential stress evaluation.

- Methods Released maturation strains along longitudinal and tangential directions were measured around the circumference of 29 Eucalyptus nitens trees, including both straight and leaning trees.

- Results Most trees produced asymmetric patterns of longitudinal maturation strain, but more than half of the maturation strain variability occurred between trees. Many trees produced high longitudinal tensile stress all around their circumference. High longitudinal tensile stress was not systematically associated with the presence of gelatinous layer. The average magnitude of released longitudinal maturation strain was found negatively
\end{abstract}

Handling Editor: Jean-Michel Leban

Contribution of the co-authors: $\mathrm{BCl}$ : co-writing of the project, experiment design, field experiments, data analysis and paper writing; JA: initiator of the collaboration, co-writing of the project, field experiments and paper reviewing; AG: field experiments; JE: field experiments; $\mathrm{BCh}$ : anatomical preparations and observations; TA: experiment design, data analysis, statistical analysis and paper writing

B. Clair · A. Gronvold · B. Chanson · T. Alméras

Laboratoire de Mécanique et Génie Civil (LMGC), CNRS,

Université Montpellier 2, cc 048, Place E. Bataillon,

34095 Montpellier, France

B. Clair $(\bowtie)$

CNRS, UMR Ecologie des Forêts de Guyane (EcoFoG), Campus

Agronomique, BP 701, 97387 Kourou, French Guiana

e-mail: bruno.clair@univ-montp2.fr

J. Alteyrac $\cdot$ J. Espejo

Facultad de Ciencias Forestales, Universidad de Concepcion,

Victoria 631, Ciudad Universitaria, Concepcion, Chile correlated to the growth rate. A methodology is proposed to ensure reliable evaluation of released maturation strain in both longitudinal and tangential directions. Tangential strain evaluated with this method was lower than previously reported.

- Conclusion The stress was always tensile along the longitudinal direction and compressive along the tangential direction, and their respective magnitude was positively correlated. This correlation does not result from a Poisson effect but may be related to the mechanism of maturation stress generation.

Keywords Longitudinal maturation stress · Tangential maturation stress · Maturation strain · Tension wood . G-layer $\cdot$ Eucalyptus nitens

\section{Introduction}

1.1 Origin and biological function of maturation stress in wood

After the cells division in the cambium and their differentiation, the maturation of the newly formed wood cells induces their tendency to shrink longitudinally and swell transversally (Fig. 1a) (Archer 1987). These strains being mostly impeded by their adherence to the older rigid cells, the cell maturation process results in a mechanical state of longitudinal tensile stress and tangential compressive stress in mature wood at tree periphery (Fig. 1b). From a mechanical viewpoint, these maturation stresses are "pre-stresses", i.e. stresses that occur during the formation of the material, prior to any external loading. Pre-stresses are beneficial for the living tree, since they optimise the behaviour of wood in response to external loading. As a honeycomb cellular material, wood has a high-tensile strength along the fibre direction but is comparatively weak in compression. Thus, if wood is subjected to local axial compression, as occurs in the inner side of a bent stem, axial buckling can be avoided by tensile pre-stresses (Bonser and 
Fig. 1 Principle of the maturation stress generation and associated strains and stress in tangential $(T)$ and longitudinal $(L)$ directions. Green cell, cell before maturation. a Red cell, theoretical view of the same cell after maturation if it was isolated from other cells. b Blue cell, realistic view of the cell after maturation considering that it sticks to older rigid cells. Green arrows represent maturation stress in the newly maturated cell, and growth stress increments that happen in the older cells in response to the maturation stress. Convergent arrows figure a state of compression, divergent arrows a state of tension. c Schematics of strains occurring after $\mathrm{T}$ or $\mathrm{L}$ unidirectional or LT bidirectional release of maturation stress induced by making grooves in the wood. The dashed blue rectangle represents the dimension of the measurement area at initial state, and the solid red rectangle its dimension after stress release. Strains are figured with blue arrows (their magnitude is amplified for the purpose of representation)
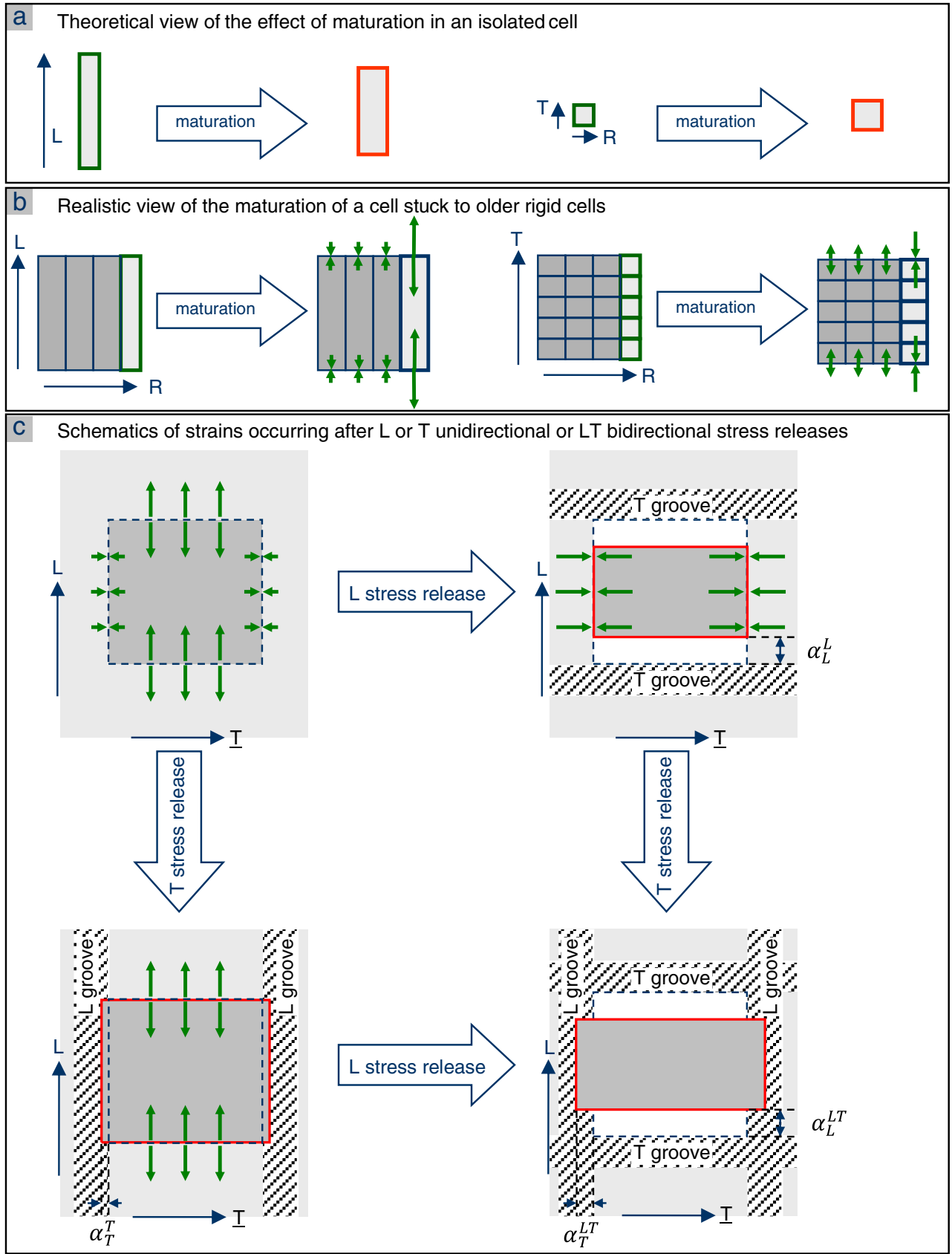

Ennos 1998). Similarly, in the tangential direction, wood can withstand compression without major damage by bending its cell walls, whereas in tension, rupture and crack propagation can easily occur. Tangential compressive pre-stress helps in preventing this situation.

These maturation stresses are also useful to trees for their postural control (Moulia et al. 2006). Trees are able to control the level of maturation stress in the produced wood and to generate asymmetrical axial stress around the stem circumference. This asymmetry generates a bending moment, allowing movement of the stem towards verticality or any preferred direction, or just to maintain a defined angle by compensating for the effect of the increasing self-weight (Alméras and
Fournier 2009). To achieve a high asymmetry, angiosperms produce very high level of tensile longitudinal stress in the inner side of the axis to be bent, through the production of a dedicated wood called tension wood. In tension wood, stresses can be more than five times higher than in normal wood. Tension wood is characterised by chemical and ultrastructural changes such as lower lignin content, more crystalline cellulose and a lower microfibril angle than in normal wood (Onaka 1949). In some species, a specific unlignified cell wall layer is formed, named gelatinous layer (G-layer). This layer is characteristic of tension wood in most temperate species. However, many species, especially in the tropical area, where most diversity can be found, have tension wood 
without G-layer (Clair et al. 2006b; Onaka 1949; Yoshida et al. 2002). Although this criterion is generally common to an entire genus, Eucalyptus has some species where tension wood with G-layer has been detected (e.g. Eucalyptus nitens), and many species producing tension wood have a lignified layer instead of the characteristic G-layer (Baillères et al. 1995; Scurfield 1972).

\subsection{Technological consequences of maturation stress}

The production of maturation stress in the newly formed wood layers is always balanced by a change in the state of stress in inner layers (Fig. 1b). Tensile longitudinal stress at the periphery induces longitudinal compression in the core of the trunk. In turn, compressive tangential stress at the periphery induces tensile tangential stress in the core of the trunk, and tensile radial stress in the whole trunk. The accumulation of these stresses during the whole tree life results in a complex stress field in the trunk, called "growth stresses" (Archer 1986; Boyd 1950a; Kubler 1987), leading to technological problems such as logend splits and heart checks during tree felling, brittle heart, and deformations of planks during sawing (Boyd 1950b; Biechele et al. 2009; Yang and Waugh 2001; Nicholson 1973). Figure 2 illustrates the log-end cracks observed few minutes after felling the tree in the eucalypts studied in the present article. These cracks are due to the combined effect of radial gradient in longitudinal growth stress and radial tensile growth stresses (Kubler 1987; Jullien et al. 2003) and clearly reduces the commercial value of logs. This problem is particularly important in eucalypt trees that generally have very high levels of maturation stress (Baillères et al. 1995; Biechele et al. 2009; Giordano et al. 1969; Jacobs 1938; Ferrand 1982c; Nicholson 1973). As the magnitude of the growth stress field primarily depends on the magnitude of maturation stress, it is important to be able to

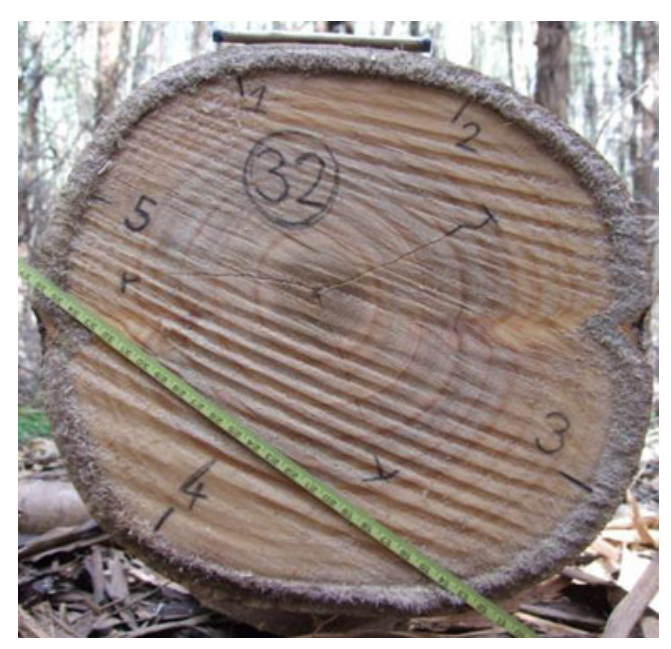

Fig. 2 Example of a butt log cross-section picture showing strain gauge locations (numbered 1-5), and cracks in the centre of the log observed few minutes after felling the tree characterise this maturation stress on the standing trees in order to predict or avoid the occurrence of such problems.

\subsection{Evaluation of longitudinal maturation stress: existing methods}

Maturation stress at the periphery of a standing tree can be evaluated by measuring the strain generated by the release of the stress. As described in earlier reviews (Archer 1986; Kubler 1987; Yang and Waugh 2001), three main methods have been used for that. The oldest methods consist in taking a piece of wood out of the trunk or log and measuring its change in dimension (Boyd 1950a; Ferrand 1982a, 1982c; Giordano et al. 1969; Jacobs 1938, 1945; Nicholson 1971; Nicholson 1973). More recent methods are both less invasive and more precise and consist in applying the stress release and strain measurement locally on the standing tree. The stress can be released by creating a free surface, either by drilling a hole or by locally sawing the wood (Fig. 1b). In the so-called "singlehole method", developed by CIRAD (Gerard et al. 1995), the displacement of two nails below and above the hole is measured, and this displacement is called growth stress indicator (GSI). This measurement (Alméras et al. 2005; Clair et al. 2003; Fournier et al. 1994; Gerard et al. 1995; Baillères et al. 1995; Biechele et al. 2009; Jullien et al. 2013), expressed in micrometres, is not directly indicating a strain but is proportional to it, with a conversion factor between 9 and $13 \mu$ strain/ $\mu \mathrm{m}$ (Fournier et al. 1994). Finally, the most popular method in recent studies consist in sawing the wood above and below an area where the strain is measured, either with a displacement transducer (Clair et al. 2006b; Fournier et al. 1994) or with a strain gauge (Alméras et al. 2005; Fang et al. 2008; Okuyama et al. 1981; Sasaki et al. 1978; Yoshida et al. 2002; Yamamoto et al. 2005). Metrological analyses of this methods can be found in Yoshida and Okuyama (2002) and Jullien and Gril (2008).

\subsection{Evaluation of tangential maturation stress: existing methods and theoretical considerations}

Most maturation stress studies concentrated on the measurement of released longitudinal maturation strains (RLMS) to evaluate maturation stress in the fibre direction because maturation stress has the highest magnitude in this direction and is directly involved in major biological functions of wood such as gravitropism (Coutand et al. 2007; Yamamoto et al. 2002) and resistance to bending loads (Bonser and Ennos 1998). Several studies also attempted to evaluate tangential stress through the released tangential maturation strains (RTMS), but this was always done in combination with longitudinal stress, by releasing the stress in both directions (Boyd 1950a; Jacobs 1945; Kubler 1959; Okuyama et al. 1981; Okuyama et al. 1994; Sasaki et al. 1978; Ferrand 1982b, 1982c). This "bidirectional" 
stress release has strong consequences on the recorded strain values and their relationship with in situ stress because of the mechanical coupling between the two directions, called the Poisson's effect.

This can be clarified by considering the case of a peripheral piece of wood in the standing tree that is put in a state of longitudinal tension $\left(\sigma_{L}>0\right)$ and tangential compression $\left(\sigma_{T}\right.$ $<0$ ) during maturation (Fig. 1c). When the stress is released in only one direction ( $\mathrm{L}$ or $\mathrm{T}$ ), then the wood strains in the same direction by an amount corresponding to the elastic response to an applied unidirectional stress $-\sigma_{L}$ or $-\sigma_{T}$, while strain are impeded in the other direction.

$\alpha_{L}^{L}=-\sigma_{L} / E_{L}^{*}$ and $\alpha_{T}^{T}=-\sigma_{T} / E_{T}^{*}$

Where $\alpha_{j}^{j}$ is the strain in direction $j$ in response to stress release in the same direction, and $E_{j}^{*}=E j\left(1-v_{T L} v_{L T}\right)$ with $E j$ is the elastic modulus of wood in direction $j, v_{T L}$ and $v_{L T}$ the Poisson's ratio, related by $v_{L T}=v_{T L} E_{L} / E_{T}$. From these equations, it is clear that the strain released in one direction is representative of the stress in the same direction. However, when the stress is simultaneously released in both directions, then the wood strains as a response to a bidirectional stress $\left(-\sigma_{L},-\sigma_{T}\right)$.

$\alpha_{L}^{L T}=-\left(\frac{\sigma_{L}}{E_{L}}-\nu_{T L} \frac{\sigma_{T}}{E_{T}}\right) \approx \alpha_{L}^{L}-\nu_{T L} \alpha_{T}^{T}$

$\alpha_{T}^{L T}=-\left(\frac{\sigma_{T}}{E_{T}}-\nu_{L T} \frac{\sigma_{L}}{E_{T}}\right) \approx \alpha_{T}^{T}-\nu_{L T} \alpha_{L}^{L}$

Where $\alpha_{j}^{L T}$ are the strains in direction $j$ in response to bidirectional stress release. These equations show that, for bidirectional stress release, the strain measured in one direction depends on the state of stress in both directions, i.e. the measurements contaminate each other as illustrated in Fig. 1c.

In the case of angiosperm woods, the usual values for Poisson's ratio range between 0.02 and 0.05 for $v_{T L}$, and between 0.3 and 0.6 for $\gamma_{L T}$ (Bergman et al. 2010). Therefore, $E_{j}^{*}$ and $E_{j}$ differ by less than $2 \%$, so that the second member of Eqs. (2) and (3) are very good approximations. Moreover, it will be shown in this article that $\alpha_{L}{ }^{L}$ is several times larger in magnitude than $\alpha_{T}^{T}$. Therefore, it can be predicted that the contamination is negligible for the longitudinally released strain, i.e. $\alpha_{L}{ }^{L T} \approx \alpha_{L}{ }^{L}$, while this contamination effect is dominant in the case of tangentially released strain; if bidirectional release is performed, then the strain recorded in the tangential direction strongly depends on the magnitude of longitudinal stress.

For this reason, in order to use released strains as an indicator of the in situ maturation stress, it is advisable to first perform the release of tangential stress by making longitudinal grooves, record unidirectionally released RTMS and then release the longitudinal stress by making tangential grooves to estimate the RLMS.

The aim of this paper is to apply this method to have precise estimates of both RTMS and RLMS in standing trees, and to assess the patterns of maturation stress in fast growing eucalyptus trees in relation to their growth rate and wood microstructure.

\section{Material and methods}

\subsection{Plant material}

Experiments were performed on 29 E. nitens H. Deane \& Maiden trees selected in a 12-year-old trial located in the region of Biobio in Chile. The stand density was 1,390 stem/hectare, with a mean tree height of $26.5 \mathrm{~m}$ and a dominant height of $34.7 \mathrm{~m}$. Trees selected for the study included both straight and leaning trees with diameter at breast height ranging from 18 to $28 \mathrm{~cm}$.

\subsection{Measurement of released strains}

Released maturation strains were measured either along the $\mathrm{T}$ and $\mathrm{L}$ directions at five positions per tree around breast height, sometimes slightly above or below in order to avoid the vicinity of branches. Position 1 was chosen on the upper side of the leaning trees, where reaction wood was expected, and randomly for straight trees, then positions 2 and 5 were picked at $45^{\circ}$ from position 1 , and positions 3 and 4 on the opposite side of positions 5 and 2, respectively (see Fig. 2). This procedure was designed to make sure there were enough measurements in the tension wood areas of leaning trees.

The procedure for measuring released maturation strains along tangential (T) and longitudinal (L) directions consisted in several steps illustrated in Fig. 3. The bark was first removed, and the cambium was peeled to ensure a correct glueing and a measurement on rigid wood. Then, biaxial strain gauges $0 / 90^{\circ}$ stacked rosette (Kyowa) were pasted parallel to the grain at each measurement position, and connected to the data logger. The data logger was initialized at this stage. Tangential release was done by two longitudinal grooves made with a sharp knife 5 to $8 \mathrm{~mm}$ away from the gauge on both sides. Groove was 2 to $5 \mathrm{~mm}$ thick to enable full dilatation of tangentially compressed wood. They were performed successively on each measurement position. Then, longitudinal release was done by sawing tangentially above and below the gauge at the same distance, successively on each measurement position. The data logger recorded the strain values of each gauge during the whole procedure. Released strain was defined as the difference between the 
Fig. 3 Step by step procedure for measurement of released maturation strains along tangential $(T)$ and longitudinal $(L)$ directions. a Remove the bark, $\mathbf{b}$ peel the cambium, $\mathbf{c}$ paste the gauges along the grain (detailed in $\mathbf{d}$ ), $\mathbf{d}$ connect to data-logger and initialize, $\mathbf{e}$ release along $\mathrm{T}$ with two grooves on both sides of each gauge and $\mathbf{f}$ release along $\mathrm{L}$ by sawing above and below each gauge

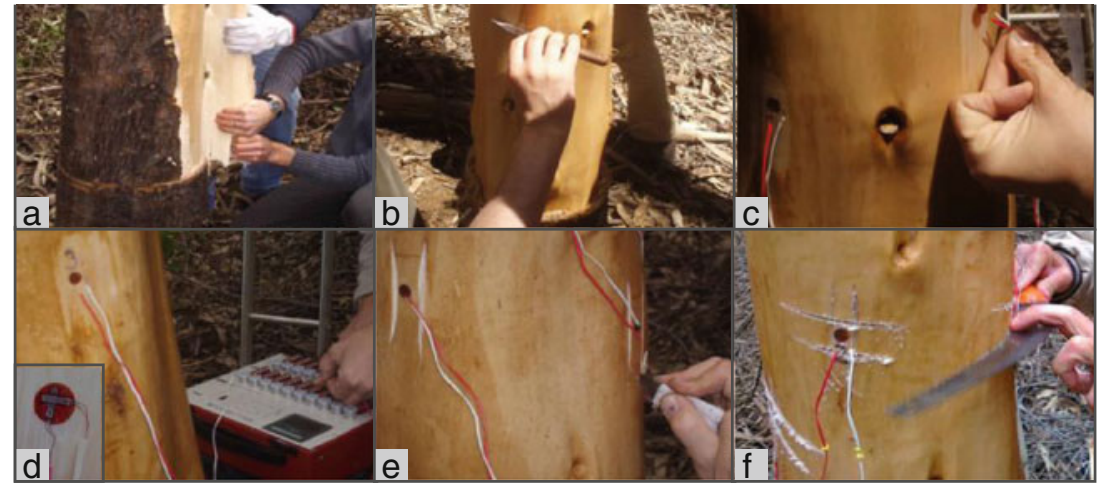

value recorded before the first groove at the first gauge and the value recorded after the second groove of the fifth gauge was completed in T direction. Similarly, in L direction, released strain was obtained from the difference between the value read before the first sawing at the first gauge and the value read after the second sawing of the fifth gauge.

\subsection{Observation of wood anatomy}

At each measurement position, transverse sections (approximately $20 \mu \mathrm{m}$ thick) were observed with a microscope to assess the presence of reaction wood. Double staining with safranin-astra blue was used to assess the presence of an unlignified G-layer, and the appearance and thickness of the cell wall was observed.

\subsection{Statistical analyses}

Statistical analyses were conducted using software Statistica ${ }^{\circledR}$. Significance of linear correlations was tested with a Fisher test. The "tree" effect on measured variables was tested using one-way ANOVA. The analysis of relationships between variables while controlling for the "tree" effect was performed using general linear model. The level of significance of all tests was $5 \%$.

\section{Results}

3.1 Effect of the stress release at a position on the strains at other positions

Figure 4 shows the $\mathrm{L}$ and $\mathrm{T}$ strains recorded at each position during the release performed in $\mathrm{L}$ and $\mathrm{T}$ directions at each position, on a representative tree. Figure 4 a shows the effect of $\mathrm{T}$ release on $\mathrm{T}$ strain, and illustrates that the release along $\mathrm{T}$ at position 1 (TRp1) not only released the strain at position 1 (TSp1) but also affected the strain at other positions (TSp2, 3, $4,5)$ in a smaller amount. Similar effect was observed later for releases at following positions, so that the $\mathrm{T}$ strain at each position increases during successive stress $T$ releases. This means that the longitudinal grooves made for tangential release at one position also affected the mechanical state of the entire cylinder. Figure $4 \mathrm{c}$ shows that, in contrast, the $T$ release had a negligible effect on $\mathrm{L}$ strains at each position. Figure $4 \mathrm{~d}$ shows that the release in the $\mathrm{L}$ direction at a given place influences $\mathrm{L}$ strains at other position in a negligible amount. Figure $4 \mathrm{~b}$ shows that $\mathrm{L}$ release at a given position has a strong effect on the $\mathrm{T}$ strain at this position (due to the Poisson's effect), and a smaller, although non-negligible, effect on the T strain at other positions (see, e.g. TSp5).

3.2 Effect of the release of longitudinal stress on the measured tangential strain

Figures 5 shows the relationships between the $\mathrm{T}$ strain recorded after unidirectional $\mathrm{T}$ release (RTMS) and that recorded after bidirectional release in both $\mathrm{T}$ and $\mathrm{L}$ directions. The correlation between these variables is strongly significant $\left(p<10^{-6}\right)$. However, when comparing to the 1:1 line, it is clear that tangential strain after bidirectional release greatly overestimates the RTMS. The slope of this relationship is more than two, showing that the coupling effect is dominant with this measurement method. The Poisson's ratio can be evaluated from this relationship, based on Eq. (3): $\vee_{L T}=\left(\alpha_{T}^{T}-\alpha_{T}{ }^{L T}\right) / \alpha_{L}{ }^{L}$. With this method, the estimated Poisson's ratio ranges between 0.2 and 0.5 , which is consistent with the usual values of this parameter.

\subsection{Patterns of released longitudinal maturation strain}

All RLMS measured during this study were negative, meaning that $\mathrm{L}$ maturation stress was always tensile. The average magnitude of RLMS was $1,382 \mu$ strains $( \pm 688$ SD). The overall variability of RLMS values was large, and more than half of it was due to a tree effect $\left(\mathrm{R}^{2}=0.57, p<10^{-6}\right)$. Figure 6 is a plot of the maximum RLMS versus the minimum RLMS measured on each tree. This figure enables the visualisation of 
Fig. 4 Example, on one of the trees, of the strains recorded along $\mathrm{T}$ and $\mathrm{L}$ at each position during the release along $\mathrm{T}$ and $\mathrm{L}$ at each position. TSpi ( LSpi) tangential (longitudinal) strain at position $i$, TRpi (LRpi) tangential

(longitudinal) release at position $i$. a $\mathrm{T}$ strain during release along $\mathrm{T}$, b $\mathrm{T}$ strain during the release along $\mathrm{L}, \mathbf{c} \mathrm{L}$ strain during the release along $\mathrm{T}, \mathbf{d} \mathrm{L}$ strain during the release along $\mathrm{L}$ a
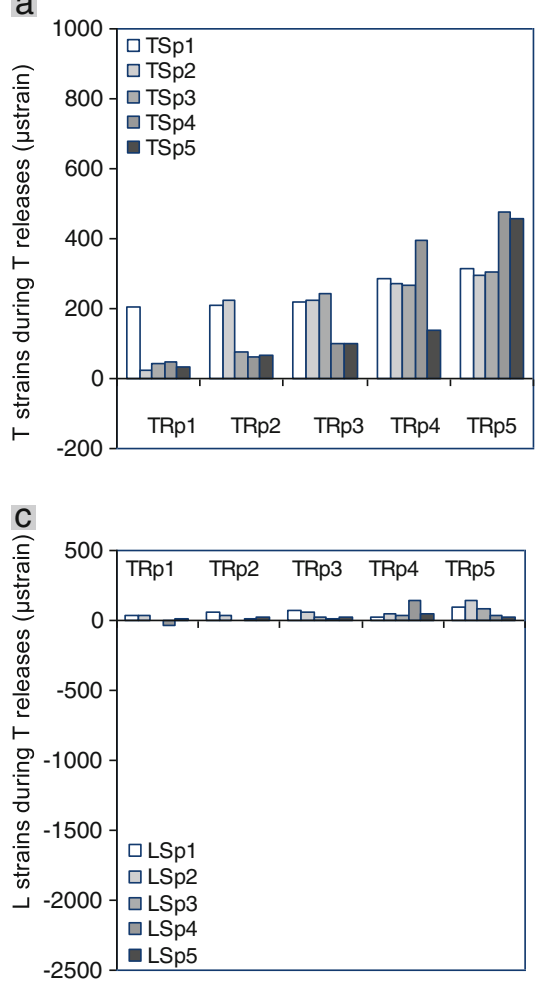

b

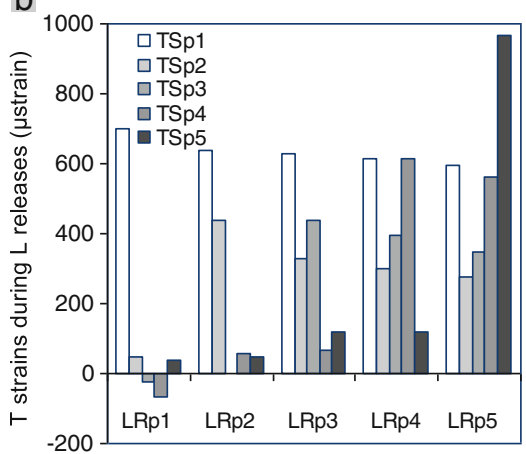

d

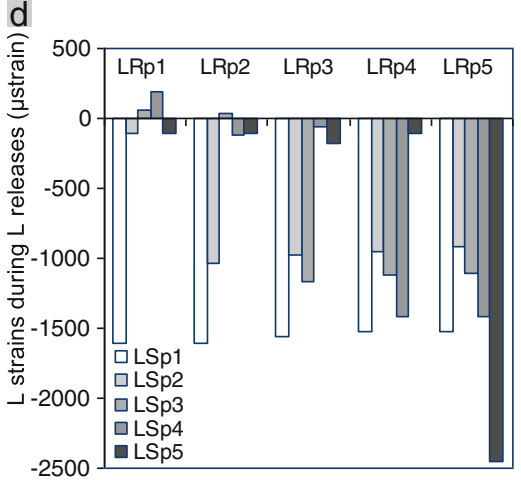

both the base stress level and the asymmetry of stress in each tree. If the maturation stress was uniform on a tree, it would be located on the diagonal; the vertical distance to the diagonal indicates the magnitude of asymmetry. Most trees present a significant asymmetry of stress, and half of the trees have their maximum RLMS at least two times higher than their minimum RLMS (dots on the right hand of the dotted line in Fig. 6). Remarkably, some trees have minimum RLMS larger than the maximum of some others.

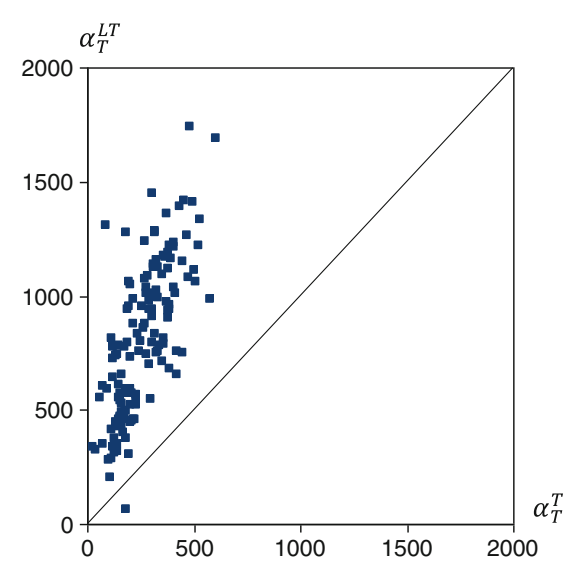

Fig. 5 Relationship between the tangential strain after unidirectional release $\left(\alpha_{T}^{T}\right)$ and after bidirectional release $\left(\alpha_{T}{ }^{L T}\right)$. Strains are expressed in microstrains $(\mu \mathrm{m} / \mathrm{m})$. Regression slope: $2.07, \mathrm{R}^{2}=0.53, p<10^{-6}$. Diagonal line indicates $y=x$

\subsection{Released tangential maturation strain}

All RTMS measured during this study were positives, meaning that $\mathrm{T}$ maturation stress was always compressive. The average value of RTMS was $264 \mu$ strains ( \pm 124 SD), i.e. approximately five times lower in magnitude than RLMS. ANOVA revealed that, similarly to RLMS, more than half of the variability was due to a tree effect $\left(\mathrm{R}^{2}=0.56\right)$. A significant correlation was found between RTMS and RLMS; the higher the L tensile stress,

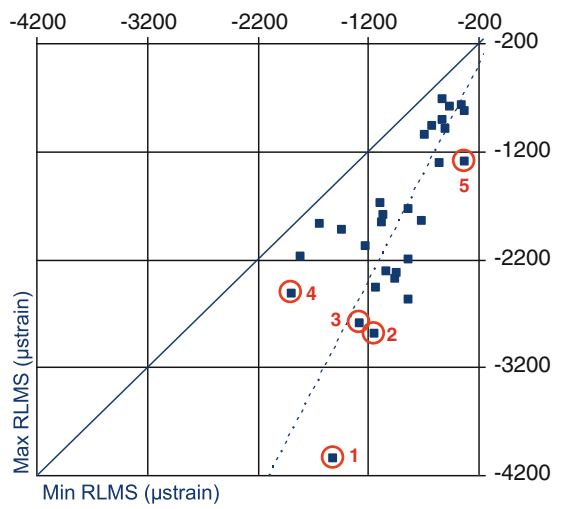

Fig 6 Plot of the maximum versus the minimum released longitudinal maturation strain $(R L M S)$ measured around each tree. Each dot is one tree. The vertical distance to the diagonal indicates the asymmetry of the RLMS around the tree. Dotted line separates trees with maximum RLMS at least two times higher than their minimum. Circles indicate trees where G-layer was found 
the higher the T compressive stress (Fig. 7). This relationship was statistically significant when all observations were pooled together $\left(\mathrm{R}^{2}=0.32, p<10^{-6}\right)$ and was even stronger when the data were averaged for each individual tree $\left(\mathrm{R}^{2}=0.55, p=0.04\right)$. General linear model taking in account a "tree" effect showed that this relationship was close to be significant $(p=0.067)$ at the within-tree level.

\subsection{Observation of wood anatomy}

Tension wood with typical G-layer was observed on 5 of the 29 trees (circled and numbered on Fig. 6). Trees 1, 2, 3 and 4 were among the highest value of maximal RLMS. Trees 1 and 4 had G-layer at all positions around the circumference. Trees 2 and 3 had G-layer only near the position of maximal RLMS. Tree 5 also had G-layer only near its position of maximal RLMS, but differed from trees 2 and 3 by its relatively low value of maximal RLMS. Nevertheless, we note that this tree had a comparatively high asymmetry (i.e. difference between maximal and minimal RLMS). In other trees, values of high RLMS were associated to a tension wood without G-layer, but instead a thick lignified secondary layer, distinctly thicker than opposite wood.

\subsection{Maturation stresses and growth rate}

Previous results indicated that the maturation strains measured at the periphery of the trunk strongly depend on a tree effect; some trees clearly have large maturation stress all around their circumference. Analysis of the relationship between the mean released maturation strain on a tree and its diameter reveals significant relationships $(p<0.001$ for both RLMS, Fig. 8a and RTMS, Fig. 8b). On even-aged plantation trees, this means that the lower the growth rate, the higher the magnitude of tensile RLMS and compressive RTMS. By contrast, the within-tree

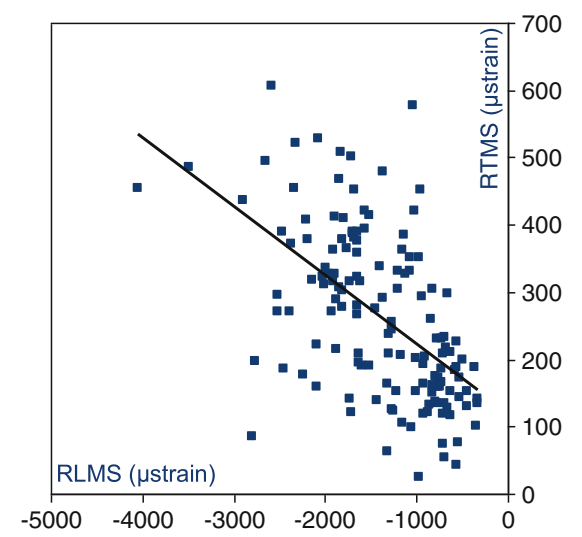

Fig. 7 Relationship between released tangential maturation strain $(R T M S)$ and released longitudinal maturation strain (RLMS) at all measured position. The correlation is statistically strongly significant $\left(\mathrm{R}^{2}=0.32, p<10^{-6}\right)$ asymmetry of RLMS (quantified as the difference between maximal and minimal RLMS within each tree) was not significantly correlated with tree diameter.

\section{Discussion}

\subsection{Metrological considerations}

Our results show that, when tangential maturation strains are measured from bidirectional stress release $\left(\alpha_{T}^{L T}\right)$, the measurement is dominated by the strong coupling effect with longitudinal stress. These results are in agreement with theoretical considerations based on wood orthotropic behaviour, and their reliability is supported by the consistency of the values of Poisson's ratio $v_{T L}$ estimated during the longitudinal stress release. This shows that, when attempting to measure both longitudinal and tangential maturation strains, it is necessary to perform the tangential release first and obtain the unidirectional tangential stress $\alpha_{T}^{T}$, as we did in this experiment, in order to have values representative and the in situ tangential stress.

Values of RTMS obtained from bidirectional stress release must be analysed with caution because, generally, they provide a significant overestimation of the strains for normal and tension wood. Results obtained on samples taken out of the trunk (Ferrand 1982a) or wood discs (Boyd 1950a; Jacobs 1945; Kubler 1959) are basically bidirectional releases. The singlehole method is also based on a bidirectional release, although its interpretation does not rely on a simple Poisson effect but on complex stress redistribution around the hole. For compression wood, in which the longitudinal stress is compressive, negative tangential strains have been reported using a bidirectional release method (Yamamoto 1998), suggesting that tensile stress, whereas the in situ stress, is actually compressive. A posteriori correction of this Poisson's effect can also be used (Okuyama et al. 1994; Sasaki et al. 1978), and data corrected with this method yield tangential strains of the same order of magnitude as our measurements. However, this technique is less straightforward, needs more measurements (values of the Young's moduli and the Poisson's ratio obtained from laboratory tests), and the results can be very sensitive to the uncertainty of these additional measurements.

By contrast, using Eq. (2) and the average values of $\alpha_{L}^{L T}, \alpha_{T}^{T}$ and $\nu_{T L}$ obtained in this experiment, it can be shown that the difference between longitudinal strain after unidirectional $\left(\alpha_{L}{ }^{L}\right)$ and bidirectional $\left(\alpha_{L}{ }^{L T}\right)$ stress release is less than $1 \%$. This means that the RLMS is almost unaffected by the release of tangential stress. Therefore, most evaluations of longitudinal maturation stress that can be found in the literature can be considered as reliable, regardless of the fact that they were obtained from unidirectional or bidirectional stress release.

Our metrological analysis also showed that tangential strain can be significantly affected by the stress release performed in 
Fig. 8 Relationships between mean maturation strains and tree diameter. Each dot is the mean over one tree. a Longitudinal maturation strain (RLMS), $\mathrm{R}^{2}=0.30, p<0.001$. b Released tangential maturation strain $\left(\right.$ RTMS), $\mathrm{R}^{2}=0.34, p<0.001$
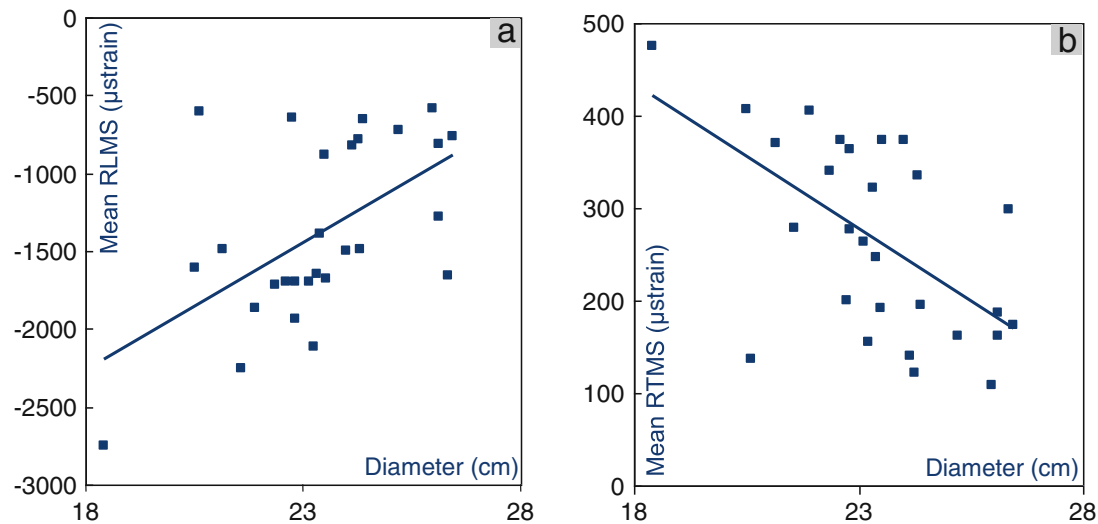

other locations of the tree. This is probably due to the complex stress redistribution that occurs when a free surface is created at one place. To address this issue, we advise to define the tangential released stress as the difference between the value read on the data logger before any groove is done on the tree, and the value obtained after the release of tangential stress at each position.

\subsection{Magnitude and distribution of L maturation stress on plantation Eucalypt trees}

The RLMS recorded on plantation Eucalypt trees was always negative. No compressive value (positive released strain) was recorded as sometimes observed in the opposite wood of angiosperm trees (Clair et al. 2006a). The asymmetric patterns observed in most trees are consistent with expectation and usual observations (Fournier et al. 1994; Jullien et al. 2013; Nicholson 1973), as most trees are more or less mechanically imbalanced and need a gravitropic correction to maintain a vertical position (Alméras and Fournier 2009).

The average level of RLMS recorded in these trees was high (approximately $-1,380 \mu$ strain) compared to usual value recorded on most species. This high level of longitudinal stress is, however, usual in eucalypt trees; in a study of Eucalyptus clones from Congo (Baillères et al. 1995), values very similar to ours are reported (average RLMS of $-1,300 \mu$ strain, maximal RLMS magnitude larger than $-3,500$ ustrain (Gerard et al. 1995)). In another study on E. nitens in Chile (Biechele et al. 2009), average values of GSI (growth stress indicator measured with the single-hole method (Gerard et al. 1995), which is correlated to RLMS (Fournier et al. 1994)), are found as high as 395 on 10-year-old plantation trees. For comparison, typical values of GSI are typically between 50 and 200 for beech (Fournier et al. 1994; Jullien et al. 2013) and chestnut (Fournier et al. 1994; Clair et al. 2003), as well as for various tropical rainforest species (Alméras et al. 2005), and lower than 150 for poplar (Alméras et al. 2005; Clair et al. 2006a). Studies by Nicholson (1973) also suggest the exceptionally high stress level of different species in the genus Eucalyptus.
For many trees, we recorded high values of RLMS all around the circumference, with a minimal value frequently larger than $-1,000 \mu$ strains. In some trees (e.g. tree 4 in Fig. 6), this minimal value was as high as $-1,900 \mu$ strains, and not associated to a strong asymmetry. Nicholson (1973) also observed many eucalypt trees with high stress level all around their circumference. This pattern is unusual; in most studies on other species, RLMS level is either low all around the circumference, revealing the absence of tension wood production, or presents high values of RLMS on only one side of the trunk, corresponding to an area of tension wood.

G-layer was observed only in some of the trees, and most of the time associated to the highest RLMS values. However, it was not observed at many positions where RLMS was more than 2,000 $\mu$ strain, revealing the presence of tension wood without G-layer. The production of tension wood without Glayer is known to happen in many species (Clair et al. 2006b; Onaka 1949), showing that G-layer is not a necessary condition for the generation of maturation stress of high magnitude. This is particularly frequent in the genus Eucalyptus (Baillères et al. 1995; Scurfield 1972). We observed that E. nitens produces tension wood both with and without G-layer. Nicholson (1973) suggests that on this species, tension wood with G-layer is only an extreme manifestation of the ability to generate stress.

\subsection{Tree effect and functional implications}

These results revealed an important "tree" effect on the distribution of maturation stress, here explaining more than half of the total variability for both RLMS and RTMS. Nicholson (1973) also observed this very important tree effect, with some trees having a high level of maturation stress all around their circumference. This tree effect was also present in a recent study on beech trees (Jullien et al. 2013), showing important coefficient of variation between trees of minimum and average RLMS levels. This shows that caution has to be taken when measurements from different trees are pooled together before the analysis. 
Moreover, from a functional viewpoint, this stress distribution cannot be explained just by the need of a gravitropic correction, since only the difference between the maximal and minimal maturation stress value is involved in this function (Alméras and Fournier 2009). This absence of gravitropic function of high stress levels has also been noticed by Nicholson (1973). Another function of longitudinal maturation stress is probably involved here; the improvement of the stem resistance against compressive failure during temporary bending loads such as wind (Bonser and Ennos 1998). This hypothesis is consistent with our observation that the mean level of maturation strain of a tree was correlated to its diameter. Although such a correlation was not detected by Nicholson (1973) in eucalypt, it has also been observed on beech trees (Jullien et al. 2013). This correlation can be interpreted through the fact that trees with smaller diameter have a lower bending stiffness due to their lower inertia, and are therefore probably more at risk regarding mechanical failure during wind loading. Tensile longitudinal pre-stress all around the circumference is an efficient way to reduce this risk.

\subsection{Growth stresses and tangential maturation stress}

The drawback for tree management is that these trees accumulate more longitudinal growth stresses. Moreover, because tensile longitudinal stress is correlated to compressive tangential stress, they also accumulate more transverse stresses. The correlation between $\mathrm{L}$ and $\mathrm{T}$ maturation stress as evaluated with our method is independent of the Poisson effect, but may be related to the mechanism of growth stress generation, that would produce lateral compression at the same time as longitudinal tension, consistently with the classical hypothesis explaining the generation of maturation stress in wood (Archer 1987).

The magnitude of released tangential strains was found about five times lower in average ( $260 \mu$ strains) than the longitudinal strain. This value is significantly lower than the figures reported in the literature, when bidirectional release was used to evaluate tangential maturation strain. Jacobs (1945) reports values ranging from 800 to $4,000 \mu$ strain on various species, Boyd (1950a) reports values between 600 and $1,600 \mu$ strain on four eucalypt species, and Kubler (1959) reports values between 1,000 and 2,600 $\mu$ strain on various species. In all these studies, the strain level is found in the same order of magnitude as in the longitudinal direction. However, in studies taking into account a posteriori correction of the Poisson's effect, lower values are reported, closer to ours: a mean value of $760 \mu$ strain for various broad-leave species (Sasaki et al. 1978) and $450 \mu$ strain for normal wood of a conifer species (Okuyama et al. 1981).

The accumulation of elastic energy in the trunk during the development of growth stresses is very probably part of the cause of the frequency of log-end splits and heart checks observed in these populations. As explained by Kubler (1987), tangential compressive stress at the periphery implies a state of radial tension in the wood of the standing tree, which is maximal in the centre. Our results show that this stress is probably lower than previously predicted in situ (Archer 1986). The major factor may be the indirect effect of the release of longitudinal stress due to the creation of a free surface when the tree is felled. This release of longitudinal stress tends to increase the state of tensile radial stress for two reasons as follows: (1) it has a direct effect on transverse stress through the material coupling effect (Poisson's ratio), so that the release of $\mathrm{L}$ compressive stress at the centre generates an important increment of radial tensile stress; (2) in addition, a structural effect due to the strong longitudinal stress gradient (tensile at the periphery, compressive at the centre) tends to bend outward each "cake" of the section, adding significant transverse stress. Heart checks happen if the transverse stress becomes larger than the tensile strength of wood. Therefore, log-end cracks are directly related to the accumulation of growth stress during tree development, in response to its biomechanical need, although they are also dependent on other wood properties such as its toughness (Jullien et al. 2013).

\section{Conclusions}

Based on careful measurements of released longitudinal and tangential maturation strains around the circumference of even-aged eucalypt plantation trees, our study leads to the main following conclusions:

- In order to evaluate the released tangential strains in the standing tree, tangential stress has to be released before the longitudinal stress, to avoid a bias due to the dominant Poisson's effect.

- All trees were in a state of tensile longitudinal stress and compressive tangential stress; the released strain being in average five times lower in magnitude in the tangential direction.

- The higher the longitudinal tensile maturation stress, the larger the tangential compressive maturation stress.

- Most trees exhibited an asymmetry of longitudinal stress around the circumference, which is interpreted as an adaption enabling to control their orientation.

- More than half of the variability of maturation stress was found at a between-tree level, with many trees producing high-longitudinal stress around their whole circumference.

- High values of longitudinal stress are often observed even in the absence of G-layer, showing that the presence of Glayer is not a necessary condition for the production of high-maturation stress in eucalypt.

- The mean stress level of trees was negatively correlated to their diameter, which is interpreted as an adaptation 
improving their resistance against temporary bending loads such as wind.

Acknowledgements This work was supported by bilateral grant from CNRS (France) and CONICYT (Chile) under the supervision of Prof. Luis Valenzuela for Chile. Many thanks are due to Jean-Pierre Lasserre (Forestal Mininco) for the access to experimental field and the help for field organisation. Luis Soto (Forestal Mininco) is also thanked for his useful help. Part of this work was performed in the framework of the project "StressInTrees" funded by the French National Research Agency (ANR-12-BS09-0004). This peer-reviewed article has been first presented in the "Trees" session of the 7th Plant Biomechanics conference.

Open Access This article is distributed under the terms of the Creative Commons Attribution License which permits any use, distribution, and reproduction in any medium, provided the original author(s) and the source are credited.

\section{References}

Alméras T, Fournier M (2009) Biomechanical design and long-term stability of trees: morphological and wood traits involved in the balance between weight increase and the gravitropic reaction. J Theor Biol 256:370-381

Alméras T, Thibaut A, Gril J (2005) Effect of circumferential heterogeneity of wood maturation strain, modulus of elasticity and radial growth on the regulation of stem orientation in trees. Trees 19:457467

Archer RR (1986) Growth stresses and strains in trees. Springer Verlag, Berlin/Heidelberg/New York

Archer RR (1987) On the origin of growth stresses in trees. Part 1: Micro mechanics of the developing cambial cell wall. Wood Sci. Technol 21:139-154

Baillères H, Chanson B, Fournier M, Tollier MT, Monties B (1995) Structure, composition chimique et retraits de maturation du bois chez les clones d' Eucalyptus. Ann Sci For 52:157-172

Bergman R, Cai Z, Carll CG, Clausen CA, Dietenberger MA, Falk RH, Frihart CR, Glass SV, Hunt CG, Ibach RE, Kretschmann DE, Rammer DR, Ross RJ, Star (2010) Wood handbook: wood as an engineering material. U.S. Department of Agriculture, Forest Service, Forest Products Laboratory., Washington D.C. (USA)/ Madison, WI, (USA)

Biechele T, Nutto L, Becker G (2009) Growth strain in Eucalyptus nitens at different stages of development. Silva Fennica 43:669-679

Bonser RHC, Ennos AR (1998) Measurement of prestrain in trees:implications for the determination of safety factors. Funct Ecol 12:971-974

Boyd JD (1950a) Tree growth stresses - Part I: growth stress evaluation. Austr J Sci Res Series B, Biological sciences 3:270-293

Boyd JD (1950b) Tree growth stresses - Part II: the development of shakes and other visual failure in timber. Aust J App Sci 1:296-312

Clair B, Alméras T, Sugiyama J (2006a) Compression stress in opposite wood of angiosperms: observations in chestnut, mani and poplar. Ann For Sci 63:507-510

Clair B, Ruelle J, Beauchêne J, Prevost MF, Fournier M (2006b) Tension wood and opposite wood in 21 tropical rain forest species. 1. Occurence and efficiency of G-layer. IAWA J 27:329-338
Clair B, Ruelle J, Thibaut B (2003) Relationship between growth stress, mechano-physical properties and proportion of fibre with gelatinous layer in Chestnut (Castanea sativa Mill.). Holzforschung 57:189-195

Coutand C, Fournier M, Moulia B (2007) The gravitropic response of poplar trunks: key roles of prestressed wood regulation and the relative kinetics of cambial growth versus wood maturation. Plant Physiol 144:1166-1180

Fang C-H, Clair B, Gril J, Liu S-Q (2008) Growth stresses are highly controlled by the amount of G-layer in poplar tension wood. IAWA J 29:237-246

Ferrand JC (1982a) Study of growth stresses. 1. Measurement method on increment cores. Ann Sci For 39:109-142 (in French with English summary)

Ferrand JC (1982b) Study of growth stresses. 2. variations in the forest of growth stresses of beech (Fagus sylvatica). Ann Sci For 39:187-218 (in French with English summary)

Ferrand JC (1982c) Study of growth stresses. 3. Eucalyptus dedegatensis and Eucalyptus nitens - influence of sylviculture and site index. Ann Sci For 39:355-378 (in French with English summary)

Fournier M, Chanson B, Thibaut B, Guitard D (1994) Measurement of residual growth strains at the stem surface. Observations of different species. Ann For Sci 51:249-266 (in French with English summary)

Gerard J, Bailleres H, Fournier M, Thibaut B (1995) Wood quality in plantation Eucalyptus - a study of variation in three reference properties. Bois For Trop 245:101-110 (in French with English summary)

Giordano G, Curro P, Ghisi G (1969) Contribution of internal stresses in wood of Eucalyptus. Wood Sci Technol 3:1-13

Jacobs MR (1938) The fibre tension of woody stems, with special reference to the genus Eucalyptus. Bull Com For Bur 22:37

Jacobs MR (1945) The growth stresses of woody stems. Commonwealth Forestry Bureau, Canberra, Australia

Jullien D, Laghdir A, Gril J (2003) Modelling log-end cracks due to growth stresses: calculation of the elastic energy release rate. Holzforschung 57:407-414

Jullien D, Gril J (2008) Growth strain assessment at the periphery of small-diameter trees using the two-grooves method: influence of operating parameters estimated by numerical simulations. Wood Sci Technol 42:551-565

Jullien D, Widmann R, Loup C, Thibaut B (2013) Relationship between tree morphology and growth stress in mature European beech stands. Ann For Sci 68:681-688

Kubler H (1959) Studies on growth stresses in trees - Part I: the origin of growth stresses and the stresses in transverse direction. Holz als Roh- und Werkstoff 17:1-9

Kubler H (1987) Growth stresses in trees and related wood properties. For Abst 48:131-189

Moulia B, Coutand C, Lenne C (2006) Posture control and skeletal mechanical acclimation in terrestrial plants: implications for mechanical modelling of plant architecture. Am J Bot 93:1477-1489

Nicholson J (1971) A rapid method for estimating the longitudinal growth stress in logs. Wood Sci Technol 5:40-48

Nicholson JE (1973) Growth stress differences in Eucalypts. For Sci 19:169-174

Okuyama T, Sasaki Y, Kikata Y, Kawai N (1981) The seasonal change in growth stress in the tree trunk. Mokuzai Gakkaishi 27:350-355

Okuyama T, Yamamoto H, Yoshida M, Hattori Y, Archer RR (1994) Growth stresses in tension wood : role of microfibrils and lignification. Ann For Sci 51:291-300

Onaka F (1949) Studies on compression and tension wood (traduction). Wood Res. 1: 1-88 traduction n.p.

Sasaki Y, Okuyama T, Kikata Y (1978) The evolution process of the growth stress in the tree. The surface stresses on the tree. Mokuzai Gakkaishi 24:140-157 (in Japenese with English summary) 
Scurfield G (1972) Histochemistry of reaction wood cell walls in two species of Eucalyptus and in Tristania Conferta R. Br Aust J Bot 20:9-26

Yamamoto H (1998) Generation mechanism of growth stresses in wood cell walls: roles of lignin deposition and cellulose microfibril during cell wall maturation. Wood Sci Technol 32:171-182

Yamamoto H, Abe K, Arakawa Y, Okuyama T, Gril J (2005) Role of the gelatinous layer on the origin of the physical properties of the tension wood of Acer sieboldianum. Wood Sci Technol 51:222-233
Yamamoto H, Yoshida M, Okuyama T (2002) Growth stress controls negative gravitropism in woody plant stems. Planta 216:280-292

Yang JL, Waugh G (2001) Growth stress, its measurement and effects. Autr For 64:127-135

Yoshida M, Ohta H, Yamamoto H, Okuyama T (2002) Tensile growth stress and lignin distribution in the cell walls of yellow poplar, Liriodendron tulipifera Linn. Trees 16:457-464

Yoshida M, Okuyama T (2002) Techniques for measuring growth stress. Holzforschung 56:461-467 